\title{
A Unified Nonlinear Adaptive Approach for Detection and Isolation of Engine Faults
}

\author{
Liang Tang \\ Impact Technologies, LLC, Rochester, New York \\ Jonathan A. DeCastro \\ Impact Technologies, LLC, Rochester, New York \\ Xiaodong Zhang \\ Wright State University, Dayton, Ohio \\ Luis Farfan-Ramos \\ Wright State University, Dayton, Ohio \\ Donald L. Simon \\ Glenn Research Center, Cleveland, Ohio
}




\section{NASA STI Program . . . in Profile}

Since its founding, NASA has been dedicated to the advancement of aeronautics and space science. The NASA Scientific and Technical Information (STI) program plays a key part in helping NASA maintain this important role.

The NASA STI Program operates under the auspices of the Agency Chief Information Officer. It collects, organizes, provides for archiving, and disseminates NASA's STI. The NASA STI program provides access to the NASA Aeronautics and Space Database and its public interface, the NASA Technical Reports Server, thus providing one of the largest collections of aeronautical and space science STI in the world. Results are published in both non-NASA channels and by NASA in the NASA STI Report Series, which includes the following report types:

- TECHNICAL PUBLICATION. Reports of completed research or a major significant phase of research that present the results of NASA programs and include extensive data or theoretical analysis. Includes compilations of significant scientific and technical data and information deemed to be of continuing reference value. NASA counterpart of peer-reviewed formal professional papers but has less stringent limitations on manuscript length and extent of graphic presentations.

- TECHNICAL MEMORANDUM. Scientific and technical findings that are preliminary or of specialized interest, e.g., quick release reports, working papers, and bibliographies that contain minimal annotation. Does not contain extensive analysis.

- CONTRACTOR REPORT. Scientific and technical findings by NASA-sponsored contractors and grantees.
- CONFERENCE PUBLICATION. Collected papers from scientific and technical conferences, symposia, seminars, or other meetings sponsored or cosponsored by NASA.

- SPECIAL PUBLICATION. Scientific, technical, or historical information from NASA programs, projects, and missions, often concerned with subjects having substantial public interest.

- TECHNICAL TRANSLATION. Englishlanguage translations of foreign scientific and technical material pertinent to NASA's mission.

Specialized services also include creating custom thesauri, building customized databases, organizing and publishing research results.

For more information about the NASA STI program, see the following:

- Access the NASA STI program home page at http://www.sti.nasa.gov

- E-mail your question via the Internet to help@ sti.nasa.gov

- Fax your question to the NASA STI Help Desk at 443-757-5803

- Telephone the NASA STI Help Desk at 443-757-5802

- Write to: NASA Center for AeroSpace Information (CASI) 7115 Standard Drive Hanover, MD 21076-1320 


\title{
A Unified Nonlinear Adaptive Approach for Detection and Isolation of Engine Faults
}

\author{
Liang Tang \\ Impact Technologies, LLC, Rochester, New York \\ Jonathan A. DeCastro \\ Impact Technologies, LLC, Rochester, New York \\ Xiaodong Zhang \\ Wright State University, Dayton, Ohio \\ Luis Farfan-Ramos \\ Wright State University, Dayton, Ohio \\ Donald L. Simon \\ Glenn Research Center, Cleveland, Ohio
}

Prepared for the

Turbo Expo 2010

sponsored by the American Society of Mechanical Engineers (ASME)

Glasgow, Scotland, United Kingdom, June 14-18, 2010

National Aeronautics and

Space Administration

Glenn Research Center

Cleveland, Ohio 44135 


\section{Acknowledgments}

This work was supported by NASA under SBIR Phase I Contract NNX09CC71P. The authors acknowledge the contributions of Jeffrey Armstrong from NASA Glenn Research Center and Dr. Al Volponi from Pratt \& Whitney. The authors would also like to thank the reviewers from NASA Glenn Research Center, Jonathan Litt, Joseph Connolly and Sanjay Garg for their comments and suggestions that greatly improved this manuscript.

Level of Review: This material has been technically reviewed by technical management.

Available from

NASA Center for Aerospace Information 7115 Standard Drive

Hanover, MD 21076-1320
National Technical Information Service 5301 Shawnee Road Alexandria, VA 22312

Available electronically at http://gltrs.grc.nasa.gov 


\title{
A Unified Nonlinear Adaptive Approach for Detection and Isolation of Engine Faults
}

\author{
Liang Tang \\ Impact Technologies, LLC \\ Rochester, New York 14623 \\ Jonathan A. DeCastro \\ Impact Technologies, LLC \\ Rochester, New York 14623 \\ Xiaodong Zhang \\ Wright State University \\ Dayton, Ohio 45435 \\ Luis Farfan-Ramos \\ Wright State University \\ Dayton, Ohio 45435 \\ Donald L. Simon \\ National Aeronautics and Space Administration \\ Glenn Research Center \\ Cleveland, Ohio 44135
}

\begin{abstract}
A challenging problem in aircraft engine health management (EHM) system development is to detect and isolate faults in system components (i.e., compressor, turbine), actuators, and sensors. Existing nonlinear EHM methods often deal with component faults, actuator faults, and sensor faults separately, which may potentially lead to incorrect diagnostic decisions and unnecessary maintenance. Therefore, it would be ideal to address sensor faults, actuator faults, and component faults under one unified framework. This paper presents a systematic and unified nonlinear adaptive framework for detecting and isolating sensor faults, actuator faults, and component faults for aircraft engines. The fault detection and isolation (FDI) architecture consists of a parallel bank of nonlinear adaptive estimators. Adaptive thresholds are appropriately designed such that, in the presence of a particular fault, all components of the residual generated by the adaptive estimator corresponding to the actual fault type remain below their thresholds. If the faults are sufficiently different, then at least one component of the residual generated by each remaining adaptive estimator should exceed its threshold. Therefore, based on the specific response of the residuals, sensor faults, actuator faults, and component faults can be isolated. The effectiveness of the approach was evaluated using the NASA C-MAPSS turbofan engine model, and simulation results are presented.
\end{abstract}

\section{Introduction}

National Transportation Safety Board accident data covering 7,571 U.S.-registered aircraft from 1980 to 2001, categorized by accident cause, reveal that 52 percent of the hardware-induced accidents were related to aircraft system malfunctions and 36 percent of these were caused by propulsion system component malfunctions (Ref. 1). Therefore, a real-time fault diagnosis scheme for aircraft engines might significantly improve flight safety by enabling accurate and early detection and isolation of incipient fault conditions.

An important area of engine health management (EHM) is sensor validation. A sensor fault may lead to poor regulation or tracking performance, or even affect the stability of the control system. Moreover, a faulty sensor output may cause inaccurate diagnostics/prognostics, resulting in unnecessary replacement of system components or mission abortion. Therefore, it is important to correctly assess the health of onboard sensors. In addition to sensors, certain propulsion system components and actuators may fail as a result of aging or damage due to harsh operating conditions or combat. Existing nonlinear EHM methods often deal with component faults, actuator faults, and sensor faults separately. Specifically, when dealing with sensor validation, people usually assume there are no component or actuator faults; when dealing with component and actuator faults, it is often assumed that there are no sensor faults. In the former case, a 
component or actuator fault may be misinterpreted as a sensor fault; in the latter case, a sensor fault may be misinterpreted as a component or actuator fault. Both cases may potentially lead to incorrect fault diagnostic decisions and unnecessary maintenance. Therefore, it would be ideal to address sensor faults, actuator faults, and component faults under one unified framework. Several researchers have investigated the development of such a unified fault diagnostic framework (Refs. 2 to 7). However, most of those results are based on linear engine models.

In addition, the desire for future propulsion systems to perform over an extended range of operating conditions, characterized by dramatic variations in dynamic pressure and nonlinear thermal dynamics, requires enhanced performance and new functionalities. Consequently, the dynamics of aircraft engines are usually highly nonlinear and rapidly changing. Many existing fault detection and isolation (FDI) methods are based on the assumption that the system exhibits linear behavior in the neighborhood of a steady-state operating point, and therefore linearization-based methods are used (e.g., the Kalman filter-based methods developed by Merrill et al. (Ref. 8) and Kobayashi and Simon (Refs. 9 and 10). Approaches that involve linearizing the engine dynamics about several steady-state operating conditions and blending parameters and controllers for these operating points tend to be rather complicated. Moreover, when the effect of various faults is taken into account, the size and complexity of the scheduling and calibration tables are significantly increased, which makes design and real-time implementation very difficult. Therefore, future EHM designs will benefit significantly from new methods that are directly based on intrinsic nonlinearities of the engine dynamics.

To address this issue, a unified nonlinear adaptive framework for detecting, isolating, and estimating sensor faults, actuator faults, and component faults for aircraft engines is developed in this paper. The presented approach is based on a bank of nonlinear fault diagnostic estimators that generate estimated measurements using advanced nonlinear adaptive estimation/learning techniques. The approach employs a nonlinear adaptive estimation architecture that is capable of directly dealing with nonlinear dynamic system models and nonlinear faults (Refs. 11). By extending the FDI logic to handle transient conditions as well as steady-state conditions, false alarms can be reduced, and early detection and isolation of sensor faults, actuator faults, and component faults can be achieved.

With the presented adaptive nonlinear FDI techniques, unstructured modeling uncertainty is taken into account to improve performance over a wide range of operating regimes. Unstructured modeling uncertainty refers to the case where the modeling uncertainty function appears possibly in all state equations without being pre-multiplied by a known distribution matrix that satisfies certain conditions. This allows us to formally introduce adaptive thresholds for both the fault detection and isolation tasks. In general, adaptive thresholds have advantages over fixed thresholds because they enhance fault sensitivity and robustness with respect to modeling uncertainty (Ref. 15). The purpose of this paper is to highlight these features using a realistic gas turbine engine simulation and to demonstrate how sensor faults, actuator faults and component faults are dealt with under a unified framework. Preliminary simulation results are presented to show the effectiveness of the approach using a transient operating scenario.

The remainder of the paper is organized as follows. First, the FDI approach is presented. Second, a neural networkbased adaptive engine model is introduced to enhance fault sensitivity and diagnostic robustness with respect to modeling uncertainty resulting from normal engine degradation. Then, the application of the techniques to a high-fidelity engine simulation is presented. Simulation results for an example transient test case are provided. Finally, conclusions and possible future work are presented.

\section{Nomenclature}

\begin{tabular}{|c|c|}
\hline C-MAPSS & $\begin{array}{l}\text { Commercial Modular Aero-Propulsion System } \\
\text { Simulation }\end{array}$ \\
\hline$D$ & Modeling uncertainties in the output equation \\
\hline $\bar{d}$ & Known bound for $d$ \\
\hline EHM & Engine Health Management \\
\hline FDE & Fault detection estimator \\
\hline FDI & Fault Detection and Isolation \\
\hline FIE & Fault isolation estimator \\
\hline $\mathrm{HPC}$ & High-pressure compressor \\
\hline HPT & High-pressure turbine \\
\hline$L$ & The number of potential sensor faults \\
\hline LPC & Low-pressure compressor \\
\hline LPT & Low-pressure turbine \\
\hline$N$ & $\begin{array}{l}\text { The number of potential component and actuator } \\
\text { faults }\end{array}$ \\
\hline Nf & Fan speed \\
\hline $\mathrm{Nc}$ & Core speed \\
\hline NN & Neural network \\
\hline P20 & Fan inlet pressure \\
\hline Ps30 & Combustor static pressure \\
\hline P50 & Core exhaust pressure \\
\hline SLS & Sea-level static (standard day) \\
\hline $\mathrm{T} 20$ & Fan inlet temperature \\
\hline $\mathrm{T} 24$ & Low-pressure compressor discharge temperature \\
\hline T48 & HPT exhaust gas temperature \\
\hline$T_{d}$ & Fault detection time \\
\hline TRA & Throttle Resolver Angle \\
\hline$U$ & System inputs \\
\hline VBV & Variable bleed valve \\
\hline VSV & Variable stator vanes \\
\hline Wf & Fuel flow rate \\
\hline$X$ & System state variables \\
\hline$Y$ & System outputs \\
\hline$\eta$ & Modeling uncertainties in the state equation \\
\hline $\bar{\eta}$ & Known bound for $\eta$ \\
\hline
\end{tabular}




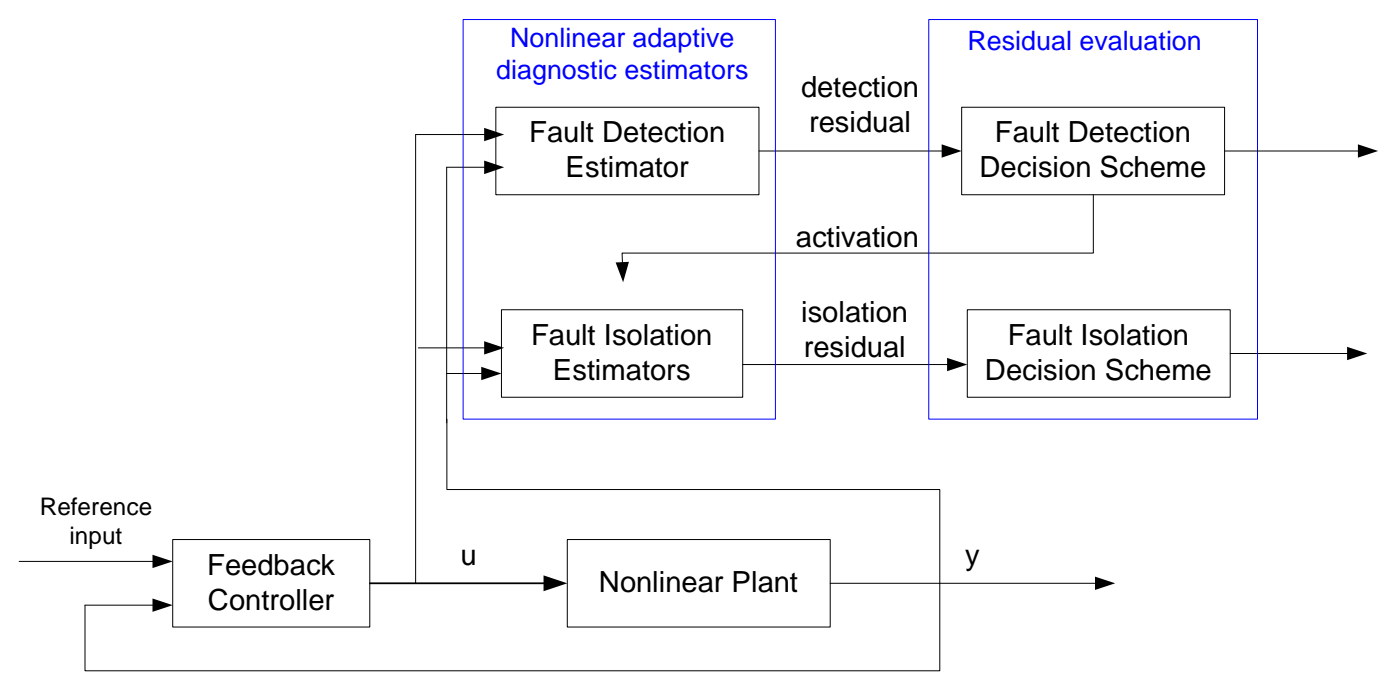

Figure 1.-Structure of nonlinear FDI (Ref. 14).

\section{Nonlinear FDI Approach}

In this section, we give a brief description of the nonlinear FDI scheme (more details can be found in Refs. 11 to 14). As shown in Figure 1, the fault detection and isolation architecture is based on a bank of $N+l+1$ nonlinear adaptive estimators, where $N$ is the number of actuator and component faults under consideration, and $l$ is the number of sensor faults. One of the nonlinear adaptive estimators is the fault detection estimator (FDE) used for detecting the occurrence of any faults, while the remaining $N+l$ nonlinear adaptive estimators are fault isolation estimators (FIEs), which are activated for the purpose of fault isolation only after a fault is detected.

Consider a generic nonlinear jet engine system described by:

$$
\begin{aligned}
& \dot{x}=A x+\gamma(x, u)+\eta(x, u, t)+\beta_{x}\left(t-T_{x}\right) \phi(x, u) \\
& y=C x+d(x, u, t)+\beta_{y}\left(t-T_{y}\right) F \theta
\end{aligned}
$$

where $x, u$, and $y$ are the state vector, input vector, and output vector of the engine system, respectively, $(A, C)$ is an observable matrix pair, and $t$ represents time. The model

$$
\begin{aligned}
& \dot{x}_{n}=A x_{n}+\lambda\left(x_{n}, u\right) \\
& y_{n}=C x_{n}
\end{aligned}
$$

represents the known nominal nonlinear dynamics of a typical new engine derived based on engine dynamics, while the healthy normal engine system is modeled by

$$
\begin{aligned}
& \dot{x}_{h}=A x_{h}+\lambda\left(x_{h}, u\right)+\eta\left(x_{h}, u, t\right) \\
& y_{h}=C x_{h}+d\left(x_{h}, u, t\right)
\end{aligned}
$$

The differences between the nominal model of Equation (2) and the healthy system model of Equation (3) are the terms $\eta$ and $d$, which represent the modeling uncertainties in the state equation and output equation, respectively. For instance, $\eta$ captures the changes in the engine dynamics as a result of normal degradation, and $d$ includes disturbances in the sensor signal.

The change in the system dynamics as a result of a sensor fault is characterized by $\beta_{y}\left(t-T_{y}\right) F \theta$ in Equation (1). Specifically, the vector $F \theta$ represents a sensor bias fault, and the function $\beta_{y}\left(t-T_{y}\right)$ characterizes the time profile of the sensor fault, where $T_{y}$ is the unknown fault occurrence time. The class of sensor bias faults under consideration is represented by $F \theta$, where $F$ is the fault distribution vector, and $\theta$ is the unknown magnitude of the sensor bias. For instance, in the presence of a single sensor fault, the sensor fault distribution vector $F$ has only one non-zero entry, which represents the corresponding corrupted output measurement. It is assumed that there are $l$ sensors being monitored. Depending on the location of the fault, the distribution vector $F$ belongs to a class of possible vectors $\left\{F^{1}, F^{2}, \ldots, F^{l}\right\}$, where, for any $j=1, \ldots, l$, only the $j$ th component of the vector $F^{j}$ takes the value of 1 , while all other components are zero. Accordingly, the scalar $\theta$ is the unknown bias in the corresponding sensor.

The change in the system dynamics as a result of a component fault or actuator fault is characterized by $\beta_{x}\left(t-T_{x}\right) \phi(x, u)$ in Equation (1). Specifically, $\beta_{x}\left(t-T_{x}\right)$ denotes the time profile of the component or actuator fault that occurs at some unknown time $T_{x}$, and $\phi(x, u)$ represents the nonlinear component or actuator fault function, which is modeled as a nonlinear function of $x$ and $u$. It is assumed that there are $N$ types of possible actuator and component faults in the fault class. Each fault function $\not p ; p=1, \ldots, N$, is described by 


$$
\phi^{p}(x, u) \triangleq\left[\left(\theta_{1}^{p}\right)^{\top} g_{1}^{p}(x, u), \ldots,\left(\theta_{m}^{p}\right)^{\top} g_{m}^{p}(x, u)\right]^{\top}
$$

where $\theta_{i}^{p}, i=1, \ldots, m$, is an estimated parameter vector assumed to belong to a known compact and convex set, $g_{i}^{p}$ is a known smooth vector field, and $m$ is the number of system state variables. As discussed in (Refs. 11 to 14), the fault model described by Equation (4) characterizes a general class of nonlinear faults where the vector field $g_{i}^{p}$ represents the functional structure of the $p$ th fault affecting the $i$ th state equation, while the unknown parameter vector $\theta_{i}^{p}$ characterizes the corresponding unknown fault magnitude.

In this research, the following assumptions are made:

1) Only one fault occurs at a time;

2) Only the case of abrupt (sudden) faults is considered. Therefore, $\beta_{x}\left(t-T_{x}\right)$ and $\beta_{y}\left(t-T_{y}\right)$ each take the form of a step function;

3) The effect of normal engine degradation is considered as modeling uncertainty, not a fault;

4) Modeling uncertainties, represented by $\eta$ and $d$ in Equation (1), are unstructured and unknown nonlinear functions of $x, u$, and $t$, but bounded, i.e., $\eta(x, u, t) \leq \bar{\eta}(y, u, t)$, and $d(x, u, t) \leq \bar{d}(y, u, t)$. The known bounds $\bar{\eta}$ and $\bar{d}$ on the unstructured modeling uncertainties are needed in order to distinguish between the effects of faults and modeling uncertainties (Refs. 11 to 14).

\section{Fault Detection Method}

The design of the fault detection estimator is based on nonlinear adaptive estimation techniques (Refs. 11 to 14). The FDE continuously monitors the behavior of the engine system based on the nominal dynamical model given by Equation (2). The FDE is designed with the hypothesis that no fault is present in the system, so if at least one of the measured variables of the real system significantly deviates from the corresponding estimate, then fault occurrence can be concluded. Therefore, the fault detection time $T_{d}$ is the time when a residual first exceeds its threshold.

If a fault is detected, it can be a sensor fault, a component fault, an actuator fault, or even some other anomalous condition. Isolation of faults (i.e., determining if a fault in the fault class under consideration has occurred) is accomplished by the fault isolation procedure described below.

\section{Fault Isolation Method}

As discussed above, the faults under consideration include $l$ types of sensor faults and $N$ types of actuator and component faults. Therefore, there are $N+l$ faults in the augmented fault class. The bank of FIEs is activated only after a fault is detected. Each adaptive FIE is designed based on the functional structure of a particular fault type. The adaptation in the FIEs arises due to the unknown fault magnitude (i.e., $\theta$ in Equation (1) and $\theta_{i}^{p}$ in Equation (4)). The adaptive law for adjusting the fault magnitude estimate is derived using a Lyapunov synthesis approach (see, for instance, (Refs. 16 to 18). Let us denote $\hat{y}^{s}(t)$ as the estimated output vector generated by the sth FIE, where $s \in\{1, \cdots, N+l\}$. The adaptive threshold for each FIE is designed in such a way that in the presence of the sth fault, the residual generated by each FIE may exceed its corresponding threshold, except for that of the $s$ th FIE.

The fault isolation scheme is developed following the general method presented in (Refs. 11 to 14). Each of the $N+l$ isolable faults will have an FIE for which a set of $l$ adaptive thresholds can be designed. Thus, if fault $s$ occurs and is detected at time instant $T_{d}$, then all $l$ components of the residual vector from the corresponding FIE (the FIE with the fault $s$ hypothesis) will remain below their adaptive thresholds for all $t \geq T_{d}$. Likewise, if at least one component of the residual vector of FIE $s$ exceeds its adaptive threshold for some finite time $t \geq T_{d}$, then the possibility of the occurrence of fault $s$ can be excluded. In other words, the FDI logic indicates that "the sth fault is isolated" if the following two conditions are met: 1) All the diagnostic residuals generated by FIE $s$ remain below their corresponding adaptive thresholds; and 2) At least one component of the diagnostic residual generated by each remaining FIE exceeds its corresponding threshold.

\section{Adaptive Thresholds for Fault Detection and Isolation}

It is well-known that modeling uncertainty has a corruptive effect on any model-based diagnostic method. As described earlier, the terms $\eta$ and $d$ in Equation (3) represent the modeling uncertainties in the state equation and output equation, respectively. In aircraft engine models, uncertainties include the effect of normal engine health degradation, engineto-engine variation, parameter variations due to dynamic operating environments, and sensor noise. Due to the presence of such modeling uncertainties, residuals are never zero even in the absence of faults. Moreover, the residual may change with the varying control inputs and dynamic operating conditions of the engine. Therefore, using a small fixed threshold may result in significant false alarms, while using a large fixed threshold may increase the number of missed detections/isolations, as illustrated in Figure 2.

In this nonlinear FDI methodology, adaptive thresholds in the form of dynamic nonlinear functions of the system inputs, outputs, and estimated parameters are rigorously established based on the bounding functions $\bar{\eta}$ and $\bar{d}$ on the modeling uncertainties and adaptive estimation techniques (Refs. 11 to 14). The FDI thresholds automatically adapt to the changing engine operating conditions and engine dynamics to enhance 


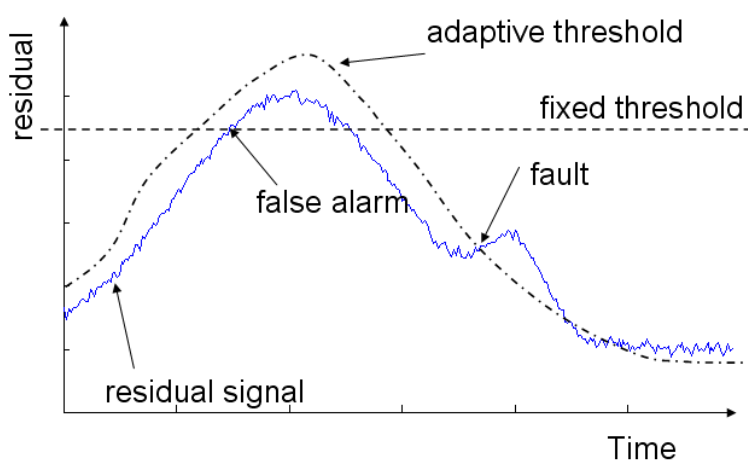

Figure 2.-Concept of adaptive thresholds in FDI.

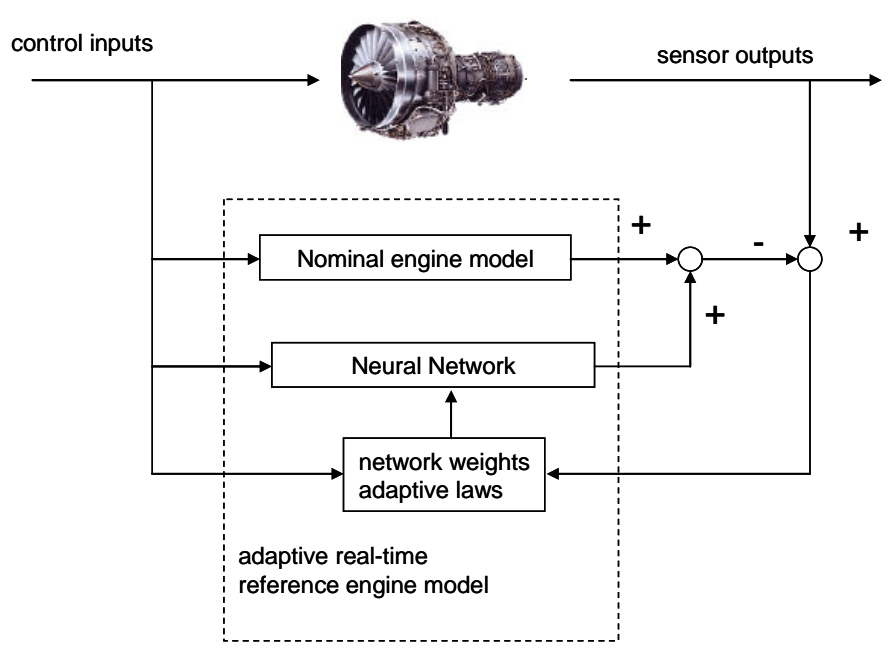

Figure 3.-Structure of the adaptive reference engine model.

the robustness and fault sensitivity of the FDI scheme. The adaptive thresholds characterize the effect of several sources of uncertainty on the FDI residual, such as modeling uncertainty $\eta$, measurement uncertainty $d$, and the estimation error of fault parameters (i.e., $\theta$ in Eq. (1) and $\theta_{i}^{p}$ in Eq. (4)). Intuitively, the smaller the uncertainty is (resulting in a smaller threshold), the easier the task of isolating the associated faults. On the other hand, the capability to isolate a fault depends not only on the significance of uncertainty, but also on the degree that the faults are mutually "different" from each other, characterized by the so-called fault mismatch function (Refs. 11 to 14).

\section{Enhancement of Robustness and Fault Sensitivity}

In this research work we also use an adaptive nonlinear reference engine model to improve the accuracy and robustness of the diagnostic method.
Similar to faults, normal engine health degradation causes the engine outputs to deviate from their reference values, which may be misinterpreted as a fault and consequently generate false alarms (Ref. 10). To compensate for deviations from the nominal engine model due to normal aging and engine-toengine variation, this FDI method uses an adaptive on-board nonlinear engine reference model as shown in Figure 3. Specifically, the reference engine model consists of a nominal engine model, representing the dynamics of a typical new engine, and a neural network- (NN-) based adaptive component for capturing various modeling errors.

One important issue that limits the practicality of adaptive reference engine models is the complexity involved in the update process. In the present method, the update process is rather simple. Specifically, the nominal engine model is fixed once designed, and weights of the neural network component are initialized to zero. Nonlinear adaptive approximation techniques (Ref. 16) are used to train the neural network on-line during flight to capture changes in engine dynamics as a result of normal aging (represented by $\eta(x, u, t)$ and $d(x, u, t)$ in Eq. (1)). If no fault is detected after a number of flights, then the reference engine model can be simply updated off-line by replacing the old neural network weights in the adaptive engine model with the new ones recently learned. Hence, the reference engine model is always a good representation of the current engine dynamics. To summarize, the learning algorithm of the neural network runs in real-time during flights, but the reference engine model is updated off-line.

\section{Application to a Commercial Engine Platform}

In this section, the generic fault diagnostic techniques described above are applied to a practical engine fault diagnosis problem. The NASA C-MAPSS engine model (Ref. 19) was utilized as an example to evaluate the performance of the presented methodology. This evaluation was accomplished by incorporating the FDI code into the C-MAPSS platform to conduct the simulation evaluations.

The C-MAPSS engine is a realistic representation of a 90,000-lb thrust class turbofan engine with high-bypass ratio and a two-spool configuration. The simulation operates with a representative closed-loop controller that regulates fan speed (Nf) by manipulating three actuators (fuel metering valve, VSV and VBV). Figure 4 shows the various components of the engine. In this engine simulation, the five rotating components consist of the fan, low pressure compressor(LPC), and low pressure turbine (LPT) on the fan shaft, and the high pressure compressor (HPC) and high pressure turbine (HPT) on the core shaft. The station designations are shown at the bottom of the figure. As shown in Table 1, C-MAPSS provides a group of health parameters that can be adjusted to simulate damage, deterioration, or fault conditions. The dynamics of several actuators and sensors have also been 


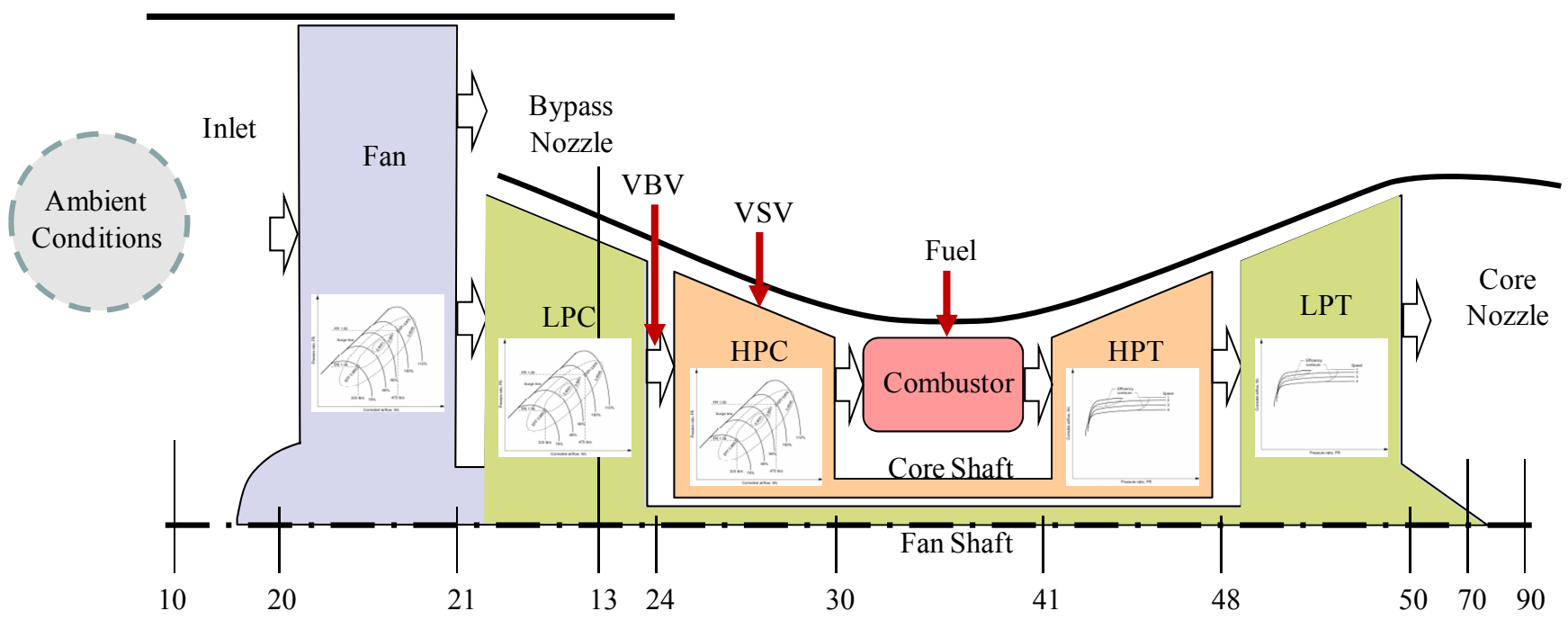

Figure 4.-Diagram of the C-MAPSS engine components and station designations (Ref. 20).

included in the simulation (see DeCastro et al. (Ref. 20)). Table 2 shows the complete set of actuators and sensors included in the simulation and their respective bandwidths.

TABLE 1.-HEALTH PARAMETERS

\begin{tabular}{|l|l|l|}
\hline & Parameter & \multicolumn{1}{|c|}{ Description } \\
\hline 1 & $\eta_{\text {mod,Fan }}$ & Fan efficiency modifier \\
2 & $\varphi_{\text {mod,Fan }}$ & Fan corrected flow modifier \\
3 & $P R_{\text {mod,Fan }}$ & Fan pressure ratio modifier \\
4 & $\eta_{\text {mod,LPC }}$ & LPC efficiency modifier \\
5 & $\varphi_{\text {mod,LPC }}$ & LPC corrected flow modifier \\
6 & $P R_{\text {mod,LPC }}$ & LPC pressure ratio modifier \\
7 & $\eta_{\text {mod,HPC }}$ & HPC efficiency modifier \\
8 & $\varphi_{\text {mod,HPC }}$ & HPC corrected flow modifier \\
9 & $P R_{\text {mod,HPC }}$ & HPC pressure ratio modifier \\
10 & $\eta_{\text {mod,HPT }}$ & HPT efficiency modifier \\
11 & $\varphi_{\text {mod,HPT }}$ & HPT corrected flow modifier \\
12 & $\eta_{\text {mod,LPT }}$ & LPT efficiency modifier \\
13 & $\varphi_{\text {mod,LPT }}$ & LPT corrected flow modifier \\
\hline
\end{tabular}

TABLE 2.-ACTUATOR AND SENSOR DESCRIPTIONS AND BANDWIDTHS

\begin{tabular}{|l|l|r|}
\hline Variable & \multicolumn{1}{|c|}{ Description } & Bandwidth \\
\hline $\mathrm{Wf}$ & Fuel metering valve & $25 \mathrm{rad} / \mathrm{s}$ \\
VBV & Variable bleed valve & $23 \mathrm{rad} / \mathrm{s}$ \\
$\mathrm{VSV}$ & Variable stator vanes & $23 \mathrm{rad} / \mathrm{s}$ \\
$\mathrm{Nf}$ & Fan speed & $50 \mathrm{rad} / \mathrm{s}$ \\
$\mathrm{Nc}$ & Core speed & $50 \mathrm{rad} / \mathrm{s}$ \\
$\mathrm{T} 20$ & Fan inlet temperature & $9 \mathrm{rad} / \mathrm{s}$ \\
$\mathrm{P} 20$ & Fan inlet pressure & $25 \mathrm{rad} / \mathrm{s}$ \\
$\mathrm{T} 24$ & LPC outlet temperature & $9 \mathrm{rad} / \mathrm{s}$ \\
$\mathrm{Ps} 30$ & Combustor static pressure & $25 \mathrm{rad} / \mathrm{s}$ \\
$\mathrm{T} 48$ & HPT exhaust gas temp. & $9 \mathrm{rad} / \mathrm{s}$ \\
P50 & Core exhaust pressure & $25 \mathrm{rad} / \mathrm{s}$ \\
\hline
\end{tabular}

The parameters in Table 3 are used in our implementation to simulate sensor noise.

TABLE 3.-PARAMETERS FOR THE SENSOR NOISE AND DYNAMICS MODULES

\begin{tabular}{|l|c|c|}
\hline \multicolumn{1}{|c|}{ Sensor } & Standard deviation & SLS* max power \\
\hline $\mathrm{Nf}$ & -- & $2388 \mathrm{rpm}$ \\
$\mathrm{Nc}$ & -- & $9048 \mathrm{rpm}$ \\
$\mathrm{T} 20$ & $1.0^{\circ} \mathrm{R}$ & $519^{\circ} \mathrm{R}$ \\
$\mathrm{T} 24$ & $2.2^{\circ} \mathrm{R}$ & $642^{\circ} \mathrm{R}$ \\
$\mathrm{T} 48$ & $2.2^{\circ} \mathrm{R}$ & $2070^{\circ} \mathrm{R}$ \\
$\mathrm{P} 20$ & $0.032 \mathrm{psi}$ & $14.6 \mathrm{psi}$ \\
Ps30 & $2.8 \mathrm{psi}$ & $523 \mathrm{psi}$ \\
P50 & $0.28 \mathrm{psi}$ & $19 \mathrm{psi}$ \\
\hline
\end{tabular}

\section{Computation of the Adaptive Thresholds}

As the engine experiences degradation with usage, the modeling discrepancies can cause the diagnostic performance to degrade; therefore adaptive FDI thresholds are employed to enhance diagnostic performance. Computation of the adaptive thresholds requires functions $\bar{\eta}$ and $\bar{d}$ that bound the uncertainties in the state equation and output equation, respectively. Since analytical forms of these equations do not exist in numerical engine simulations such as C-MAPSS, a more direct modeling approach must be employed. In the modeling scheme shown in Figure 5, the healthy engine model is an adaptive model that includes a $\mathrm{NN}$ component representing normal engine degradation. The degraded C-MAPSS engine model is fed by an assumed "worst-case" health parameter combination $(\Delta h)$ that can occur during the 
NN training cycle. As such, the functions $\bar{\eta}$ and $\bar{d}$ are taken as representations of the worst-case mismatch (uncertainty) between the model and actual engine. These dynamic functions are characterized by the degradation incurred during a small number of flights and are utilized to calculate the adaptive thresholds at each time step.

\section{Engine FDI Algorithm}

A proof-of-concept FDI algorithm, designed to detect and isolate six faults, was implemented and integrated into the CMAPSS engine model. The six fault types are listed in Table 4. As shown in Figure 6, the prototype software consists of one FDE and six FIEs, one for each fault type. The sensor, actuator, and component faults considered in this work are a representative subset of faults that are considered relatively challenging to detect/isolate. For instance, the $\mathrm{Nf}$ sensor fault mode was selected because the primary engine fuel flow (Wf) controller uses the Nf variable for feedback. Therefore, Nf sensor faults may be masked by the control system as it regulates that variable. The sensed $\mathrm{Nc}$ and T24 values are used for scheduling the variable stator vanes (VSV). Therefore, studying the Nc and T24 sensors is of interest because shifts in those sensors can be possibly misinterpreted as a fault in VSV (and vice versa). Lastly, the HPC component fault was selected because it can possibly be misinterpreted as a fault in the VBV or VSV actuators due to the physical coupling. In this paper, HPC faults are modeled simply as commensurate step decreases in the HPC efficiency and flow capacity.

The engine FDI logic is as follows. The engine FDI declares that "fault $s$ is isolated" if the following two conditions are both met:

- All the diagnostic residuals generated by FIE $s$ remain below their corresponding adaptive thresholds.

- At least one component of the diagnostic residual generated by each remaining FIE exceeds its corresponding adaptive threshold.

Note that the fault can be a sensor fault (Nf, Nc, and T24), an actuator fault (Wf and VSV), or a component fault (HPC). This FDI logic is illustrated schematically in Figure 7. Note that in this figure three residual signals (Nf, Nc and T24) are generated by each FIE as an example. The number of residual signals may be increased when more sensor faults need to be considered. Particularly, "0" indicates the residual always remains below its threshold, while " 1 " indicates the residual exceeds its threshold at some finite time. When there is only one " 0 " in the isolation indicator, the fault is successfully

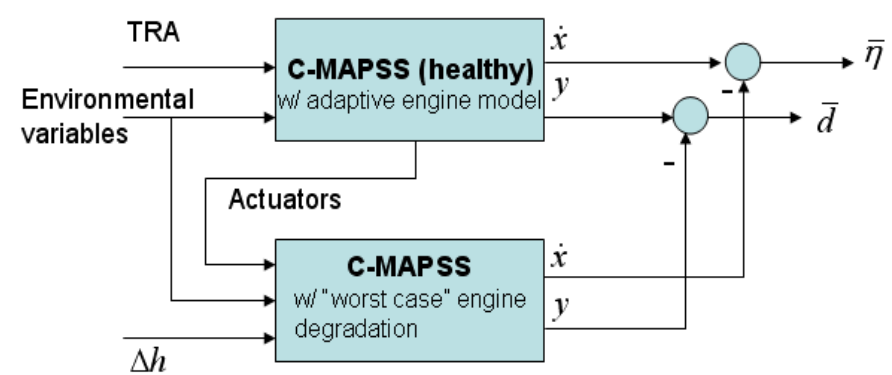

Figure 5.-Approach for determining parameters used to compute adaptive thresholds.

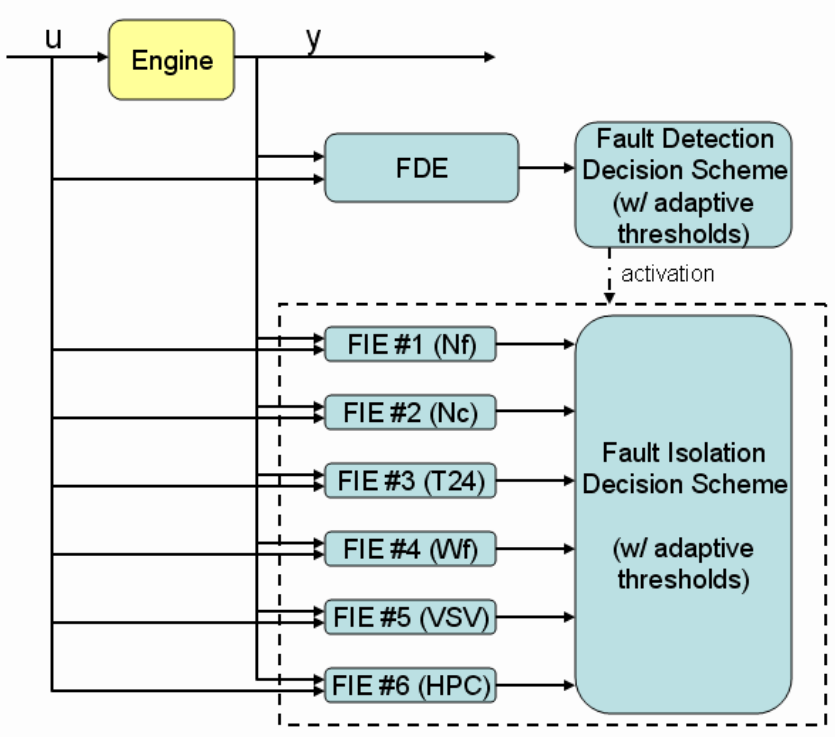

Figure 6.-A prototype FDI implemented for proof-ofconcept demonstration.

TABLE 4.-FAULTS CONSIDERED

IN THE SIMULATION STUDY

\begin{tabular}{|l|l|}
\hline \multicolumn{1}{|c|}{ Fault type } & \multicolumn{1}{c|}{ Failure mode } \\
\hline Nf sensor & Bias in sensor reading \\
Nc sensor & Bias in sensor reading \\
T24 sensor & Bias in sensor reading \\
Wf actuator & Bias in actuator output \\
VSV actuator & Bias in actuator output \\
HPC & Abrupt fault resulting in changes of the \\
& health parameter values in HPC \\
\hline
\end{tabular}


isolated. If there is no " 0 ", the fault detected is an unexpected fault. When there are multiple "0"s, the fault is not isolable among the faults whose corresponding FIEs give " 0 "s. Note that the fault isolability depends on the interplay between modeling uncertainty and the difference between faults. The fault isolability conditions have been rigorously investigated by using the so-called fault mismatch function, which characterizes the differences between faults (Refs. 11 to 14).

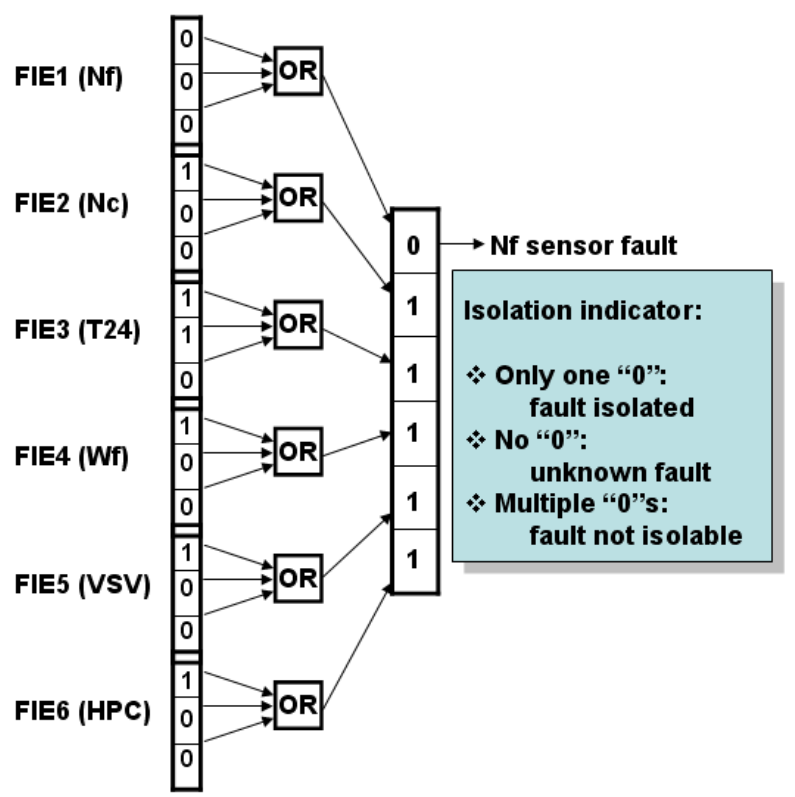

Figure 7.-Implementation of fault isolation logic.

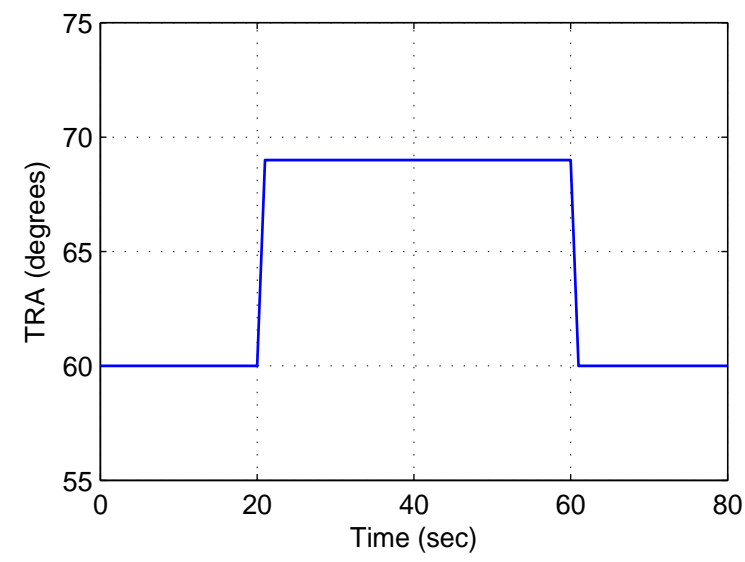

Figure 8.-Time history of the transient scenario considered.

\section{Simulation Results-Transient Example}

To evaluate the proof-of-concept nonlinear FDI scheme, a simulation study for all six fault modes was successfully conducted and demonstrated using the C-MAPSS engine model. In this initial work, only one transient example was explored. To test the approach in a time-varying operating scenario, a transient scenario similar to that in Kobayashi and Simon (Ref. 10) was used. The throttle resolver angle (TRA) was ramped from $60^{\circ}$ to $69^{\circ}$ in 1 sec. After steady-state operation, the TRA was ramped back to $60^{\circ}$ in $1 \mathrm{sec}$, as shown in Figure 8. The altitude and Mach number were held constant at $25000 \mathrm{ft}$ and 0.62 , respectively. In this example, the difference between the engine model and the real engine (for instance, due to normal degradation) is a represented by a -0.2 percent shift in each of LPC efficiency, LPC flow capacity, HPC efficiency, and HPC flow capacity.

Simulation results were generated for all six faults with different fault sizes. The FDI software successfully detected and isolated all six faults as long as the simulated fault magnitude was larger than a minimum detectable/isolable size (to be discussed next), and no misdiagnosis occurred. In addition to fault diagnosis, the adaptive FIEs also provide an estimate of the fault size ( $\theta$ in Eq. (1) and $\theta_{i}^{p}$ in Eq. (4)), which can potentially be utilized for automated fault accommodation.

For the sake of space, only the simulation results of the $\mathrm{Nf}$ (fan speed) sensor bias fault are presented here as an illustrative example. In this simulation study, the neural network-based adaptive element is not activated. Figures 9, 10 and 11 correspond to the case of a $20 \mathrm{rpm}$ bias (nearly 1 percent of the simulated operating condition) in the $\mathrm{Nf}$ sensor signal, which occurred at $\mathrm{t}=35 \mathrm{sec}$. As can be seen in Figure 9, the fault was detected at $t=35.1 \mathrm{sec}$. The estimated $\mathrm{Nf}$ fault magnitude is $22 \mathrm{rpm}$ (shown in Fig. 10), which is very close to the actual fault size $(20 \mathrm{rpm})$. The small discrepancy in the sensor bias estimation is due to the modeling error simulated by introducing nominal engine degradation. The steady-state bias estimate is even closer to the actual fault size when no modeling error is present. Figure 11 shows the time history plots of the three residuals generated by each of the six FIE's, along with their corresponding residual thresholds. Since the FIEs are activated only if a fault is detected by the FDE, the time scale on all six subplots begins at $t=35.1 \mathrm{sec}$. As shown in Figure 11, the single FIE for which all the residuals always remain below their corresponding thresholds was designed on the hypothesis of an Nf bias fault, while at least one component of the diagnostic residuals generated by each remaining FIE exceeds its threshold almost immediately following the positive fault detection decision. By applying the fault isolation logic shown in Figure 7, an $\mathrm{Nf}$ bias is isolated by the FDI algorithm. 

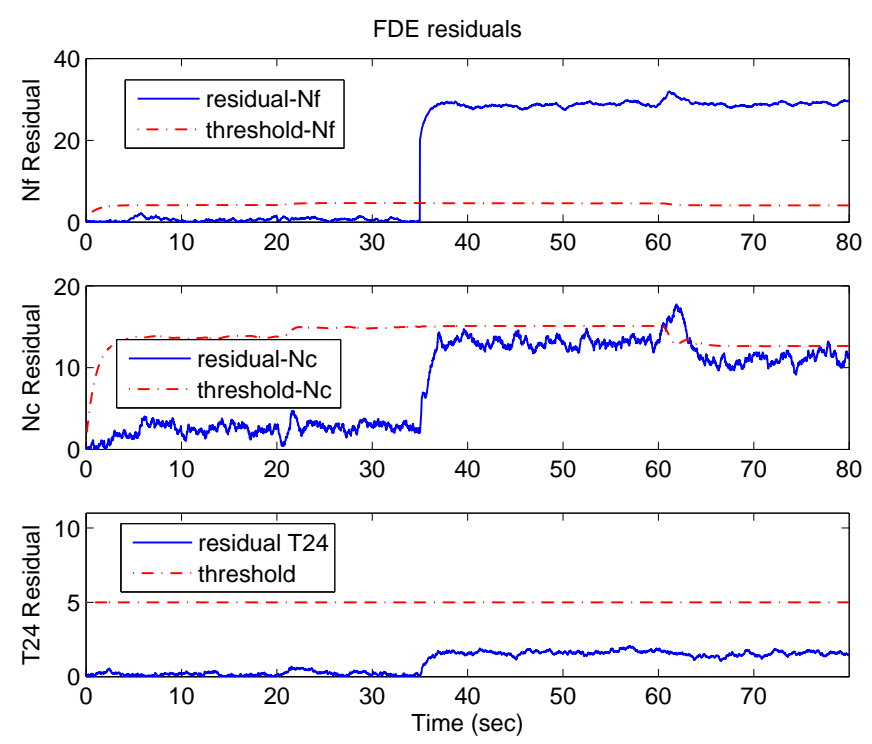

Figure 9.--Residuals generated by the FDE and adaptive thresholds ( $\mathrm{Nf}$ bias $=20$, fault occurrence time $=35 \mathrm{sec}$ ).

In addition, a study of the minimum detectable and isolable fault size for all six fault modes was conducted. The results are summarized in Table 5, using the transient scenario in Figure 8 as before. From this study, the following observations can be seen. First, the results indicate that the nonlinear FDI can correctly detect and isolate faults in each of the chosen sensor, actuator, and engine components. Second, in each case, the minimum detectable and isolable faults are within 5 percent of the steady-state value and many are significantly less, which is a promising result for detecting small-scale though process noise and a transient operating scenario were considered in this evaluation. Initial development of a NNbased adaptive reference engine model was also conducted for

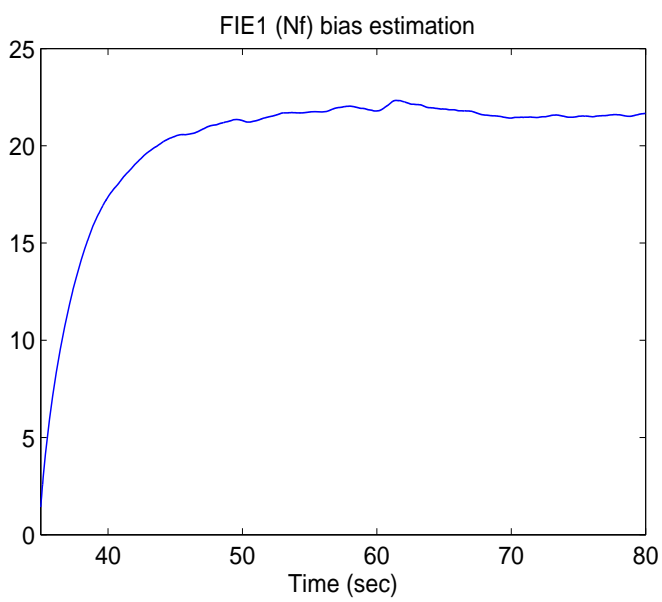

Figure 10.—Nf sensor fault bias estimation.

faults. Third, in no case was a false alarm generated even enhancing fault sensitivity and robustness to modeling uncertainty. As an example, a preliminary result is shown in Figure 12. In this example, the simulated engine degradation includes 0.3 percent losses in fan efficiency and flow capacity, 0.3 percent losses in LPC efficiency and flow capacity, and 0.3 percent losses in HPC efficiency and flow capacity. No faults were present in the system. The $\mathrm{NN}$ was trained during the first $15 \mathrm{sec}$. The training was then stopped, and then the NN with the trained weights was utilized for the rest of the simulation. In Figure 12, it is obvious that the Nc residual was reduced significantly after the $\mathrm{NN}$ was trained and utilized in the engine model.

The NN can be trained either off line or online in parallel with the FDI system but is not used in the FDI system while the NN is being trained. The NN in the FDI system is updated as necessary after a number of flights. The adaptive thresholds are affected when the adaptive engine model is updated.

TABLE 5.-MINIMUM DETECTABLE AND ISOLABLE FAULT SIZE

\begin{tabular}{|l|c|c|c|}
\hline \multicolumn{1}{|c|}{ Fault type } & $\begin{array}{c}\text { Minimum detectable fault size } \\
(\% \text { of SLS) }\end{array}$ & $\begin{array}{c}\text { Minimum isolable fault size } \\
\text { (\% of SLS) }\end{array}$ & Estimated fault size \\
\hline Nf sensor bias & $5(0.21 \%)$ & $10(0.42 \%)$ & 11.2 \\
Nc sensor bias & $16(0.18 \%)$ & $25(0.28 \%)$ & 23.7 \\
T24 sensor bias & $5(0.78 \%)$ & $11(1.6 \%)$ & 11.1 \\
Wf actuator bias & $-120(0.49 \%)$ & $-125(0.52 \%)$ & -110 \\
VSV actuator bias & $-0.20(3.39 \%)$ & $-0.25(4.24 \%)$ & -0.21 \\
HPC efficiency and flow capacity loss & $-0.009(0.9 \%)$ & $-0.015(1.5 \%)$ & -0.016 \\
\hline
\end{tabular}


FIE 1 (Nf)
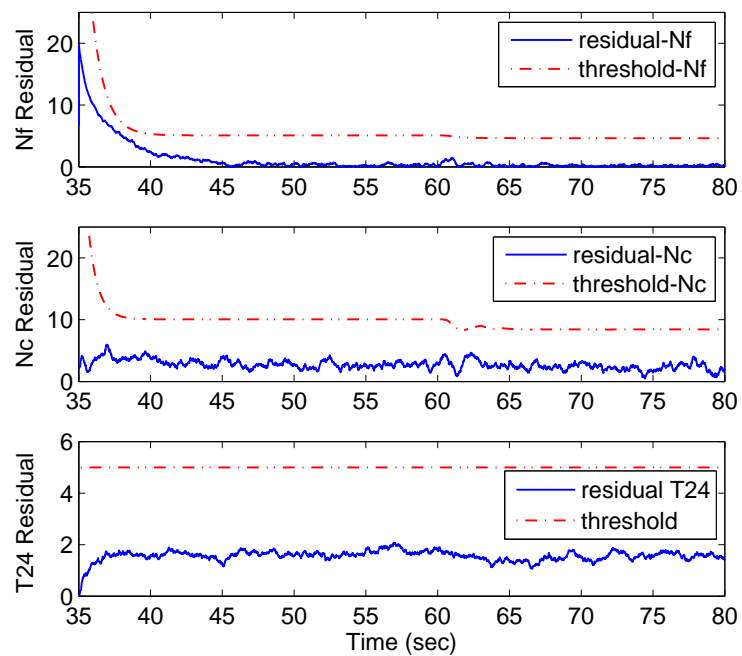

(a) FIE no. 1; none of the thresholds exceeded

FIE 3 (T24)
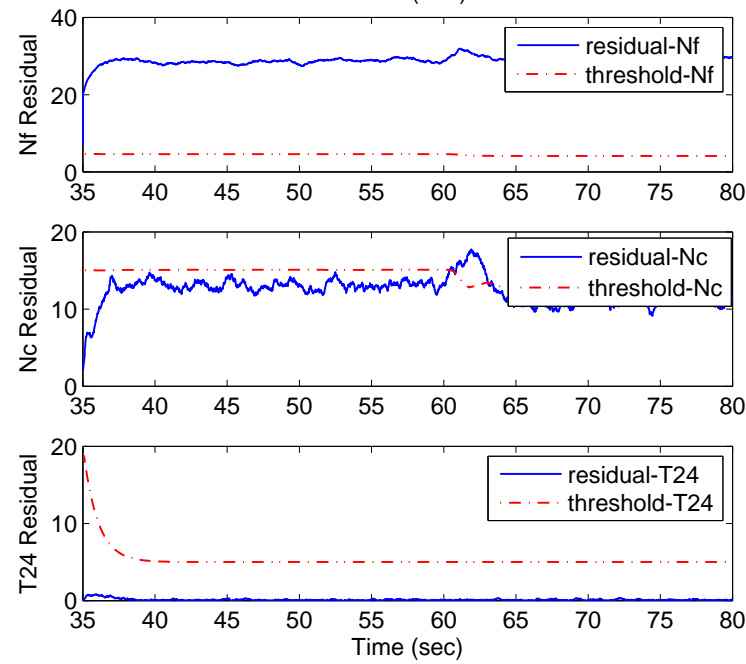

(c) FIE no. 3; the Nf residual exceeds threshold FIE 5 (VSV)
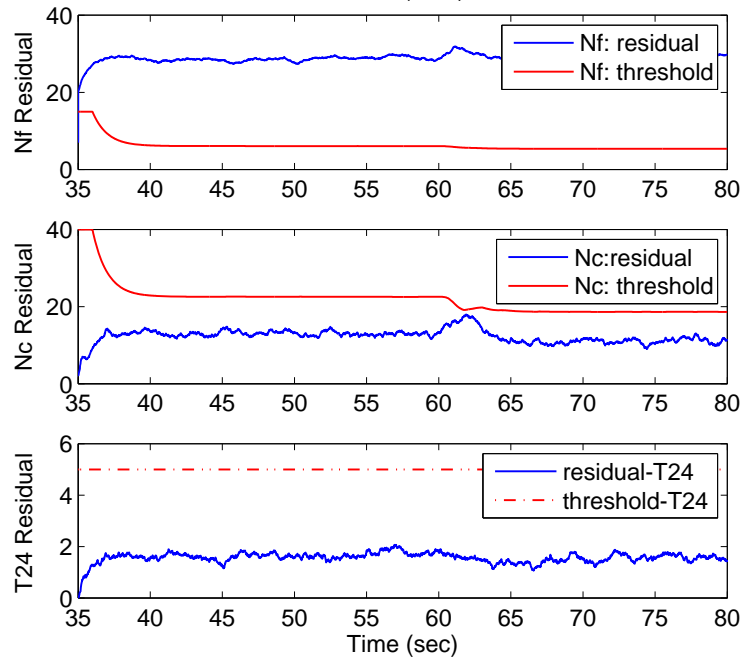

(e) FIE no. 5; the Nf residual exceeds threshold
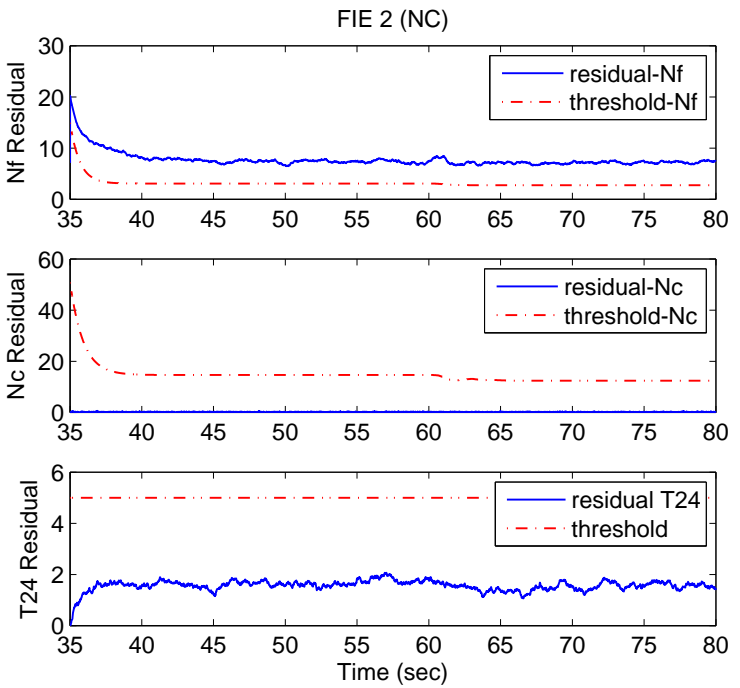

(b) FIE no. 2; the Nf residual exceeds threshold $\mathrm{FIE} 4(\mathrm{Wf})$
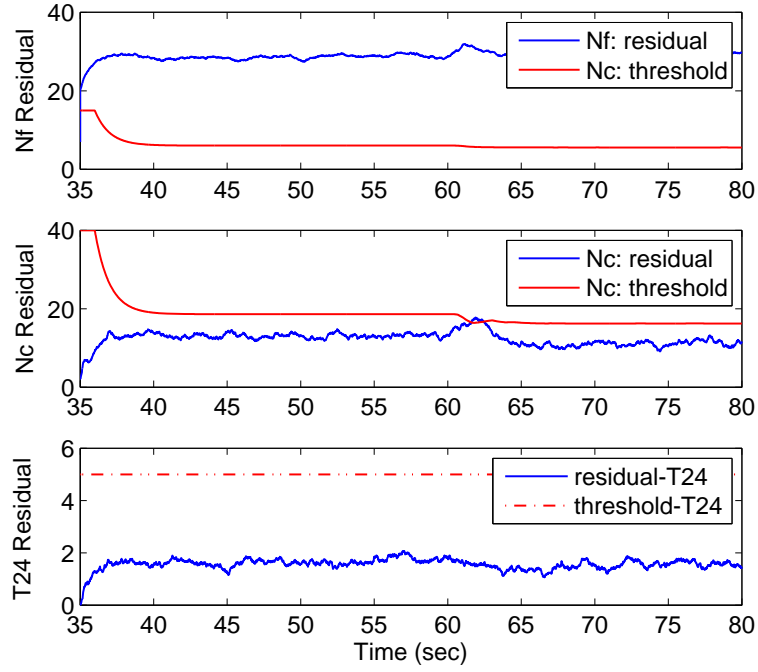

(d) FIE no. 4; the Nf residual exceeds threshold
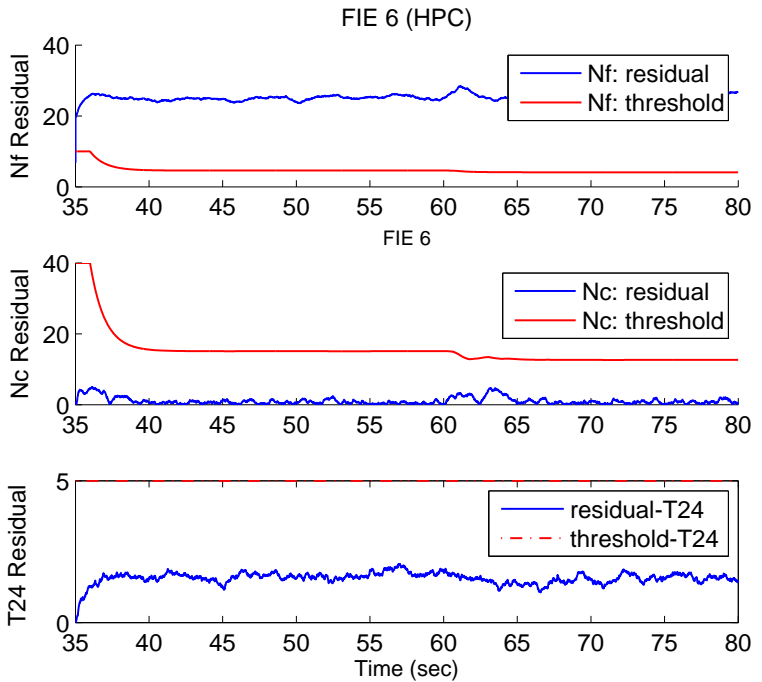

(f) FIE no. 6; the Nf residual exceeds threshold

Figure 11.- Sensor residuals generated by the FIEs and their adaptive thresholds for Nf sensor fault scenario. 


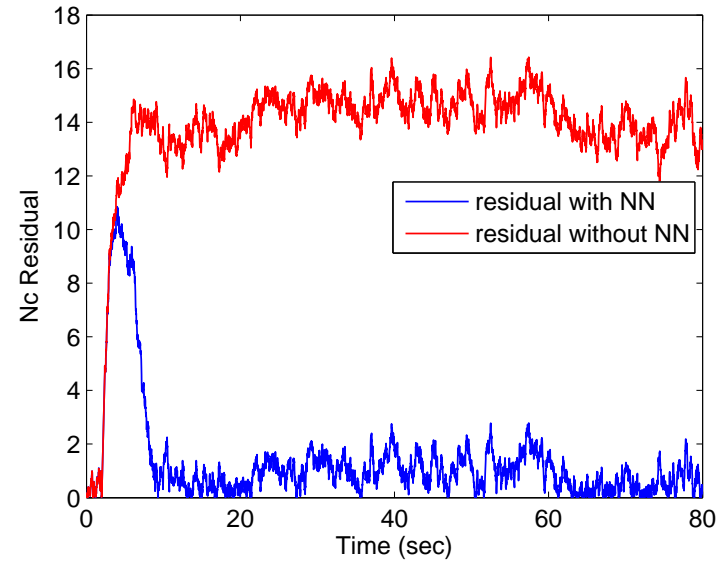

Figure 12.-NN enhancement simulation results.

\section{Conclusions and Future Work}

In this paper a new methodology for model-based fault detection and isolation (FDI) that is based on a unified nonlinear adaptive framework is described. The FDI architecture is capable of detecting and isolating sensor faults, actuator faults, and component faults in aircraft engines using a parallel bank of nonlinear adaptive estimators. The framework makes use of adaptive thresholds that intrinsically capture the nonlinear behavior of the engine, thereby addressing the limitations of fixed or scheduled thresholds. The approach was evaluated on the C-MAPSS engine model, revealing the promise of the approach for engine FDI.

Although the results are promising, the evaluation of the algorithm presented in this paper is preliminary. In order to gain confidence in the technique, it is necessary to perform the following tasks. First, to compensate for modeling errors such as normal aging and engine-to-engine variation, it will be necessary to develop an adaptive real-time nonlinear engine model using neural network (NN) techniques, as discussed in this paper. The preliminary development of NN-based adaptive reference engine models will need to be further explored. Second, it is necessary to redevelop the FDI scheme by considering the full suite of sensors, actuators, and engine component faults. Once the full FDI system is developed, it is necessary to statistically characterize the performance of the algorithm at various flight conditions and levels of degradation and evaluate the false alarms and missed detections. Lastly, deployment of the code on a physical test bed is necessary for maturation of the technology.

\section{References}

1. NASA IVHM $\quad \begin{gathered}\text { Technical Plan, } \\ \text { http://www.aeronautics.nasa.gov/nra_pdf/ivhm tech_plan_c1.pdf, }\end{gathered}$
accessed November 2009.
2. Grodent, M., and Navez, A., 2001, "Engine Physical Diagnosis
using a Robust Parameter Estimation Method," 37th

AIAA/ASME/SAE/ASEE Joint Propulsion Conference, AIAA2001-3768.

3. Volponi, A. J., 2003, Foundation of Gas Path Analysis (Part I and II), von Karman Institute Lecture Series: Gas Turbine Condition Monitoring and Fault Diagnosis, 2003-01.

4. Volponi, A. J., DePold, H., Ganguli, R., and Daguang, C., 2003, "The Use of Kalman Filter and Neural Network Methodologies in Gas Turbine Performance Diagnostics: A Comparative Study," J. of Engineering for Gas Turbines and Power, 125, 917-924.

5. Dewallef, P., and Léonard, O., 2003, "On-Line Performance Monitoring and Engine Diagnostic Using Robust Kalman Filtering Techniques," ASME Paper GT2003-38379.

6. Surrender, V., and Ganguli, R., 2004, "Adaptive Myriad Filter for Improved Gas Turbine Condition Monitoring Using Transient Data," ASME Paper GT2004-53080.

7. Borguet, S., and Léonard, O., 2008, "A Sensor-Fault-Tolerant Diagnosis Tool Based on a Quadratic Programming Approach," Journal of Engineering for Gas Turbines and Power, 130, No 2, DOI: $10.1115 / 1.2772637$.

8. Merrill, W.C., DeLaat, J.C., and Abdel-Wahab, M., 1991, "Turbofan Engine Demonstration of Sensor Failure Detection," J. of Guidance, Control, and Dynamics, 14 (2), pp. 337-349.

9. Kobayashi, T., and Simon, D.L., 2003, "Application of a Bank of Kalman Filters for Aircraft Engine Fault Diagnostics," ASME Paper GT2003-38550.

10. Kobayashi, T., and Simon, D.L., 2006, "Hybrid Kalman Filter Approach for Aircraft Engine In-Flight Diagnostics: Sensor Fault Detection Case," ASME Paper GT2006-90870.

11. Zhang, X., Polycarpou, M.M., and Parisini, T., 2010, "Fault Diagnosis of a Class of Nonlinear Uncertain Systems with Lipschitz Nonlinearities Using Adaptive Estimation," Automatica, 46 (2), pp. 290-299.

12. Zhang, X., Polycarpou, M.M., and Parisini, T., 2002, “A Robust Detection and Isolation Scheme for Abrupt and Incipient Faults in Nonlinear Systems," IEEE Transactions on Automatic Control, 47 (4), pp. 576-593.

13. Zhang, X., Parisini, T., and Polycarpou, M.M., 2005, "A Sensor Bias Fault Isolation Scheme for a Class of Nonlinear Systems," IEEE Transactions on Automatic Control, 50 (3), pp. 370-376.

14. Zhang, X., Polycarpou, M.M., and Parisini, T., 2008, "Design and Analysis of a Fault Isolation Scheme for a Class of Uncertain Nonlinear Systems," IFAC Annual Reviews in Control, 32, pp. 107-121.

15. Chen, J., and Patton, R. J., 1999, Robust Model-Based Fault Diagnosis for Dynamic Systems, London:Kluwer.

16. Farrell, J., and Polycarpou, M.M., 2006, Adaptive Approximation Based Control: Unifying Neural, Fuzzy and Traditional Adaptive Approximation Approaches, Wiley Interscience.

17. Ioannou, P. A., and Sun, J., 1995. Robust adaptive control, Englewood Cliffs, NJ: Prentice Hall.

18. Vemuri, A. T., and Polycarpou, M. M., 1997, "Robust nonlinear fault diagnosis in input-output systems," International Journal of Control, 68, 343-360.

19. Frederick, D.K., DeCastro, J.A., Litt, J.S., (2007), “User's Guide for the Commercial Modular Aero-Propulsion System Simulation (C-MAPSS)," NASA/TM-2007-215026.

20. DeCastro, J.A., Litt, J.S., and Frederick, D.K., 2008, "A Modular Aero-Propulsion System Simulation of a Large Commercial Aircraft Engine," 44th AIAA/ASME/SAE/ASEE Joint Propulsion Conference \& Exhibit, AIAA-2008-4579. 


\begin{tabular}{|c|c|c|}
\hline \multicolumn{2}{|c|}{ REPORT DOCUMENTATION PAGE } & $\begin{array}{l}\text { Form Approved } \\
\text { OMB No. 0704-0188 }\end{array}$ \\
\hline \multicolumn{3}{|c|}{$\begin{array}{l}\text { The public reporting burden for this collection of information is estimated to average } 1 \text { hour per response, including the time for reviewing instructions, searching existing data sources, gathering and maintaining the } \\
\text { data needed, and completing and reviewing the collection of information. Send comments regarding this burden estimate or any other aspect of this collection of information, including suggestions for reducing this } \\
\text { burden, to Department of Defense, Washington Headquarters Services, Directorate for Information Operations and Reports (0704-0188), } 21215 \text { Jefferson Davis Highway, Suite } 1224 \text {, Arlington, VA } 22222-24302 \text {. } \\
\text { Respondents should be aware that notwithstanding any other provision of law, no person shall be subject to any penalty for failing to comply with a collection of information if it does not display a currently valid OMB } \\
\text { control number. } \\
\text { PLEASE DO NOT RETURN YOUR FORM TO THE ABOVE ADDRESS. }\end{array}$} \\
\hline $\begin{array}{l}\text { 1. REPORT DATE (DD-MM-YYYY) } \\
01-07-2010\end{array}$ & $\begin{array}{l}\text { 2. REPORT TYPE } \\
\text { Technical Memorandum }\end{array}$ & 3. DATES COVERED (From - To) \\
\hline \multirow{3}{*}{\multicolumn{2}{|c|}{$\begin{array}{l}\text { 4. TITLE AND SUBTITLE } \\
\text { A Unified Nonlinear Adaptive Approach for Detection and Isolation of Engine Faults }\end{array}$}} & 5a. CONTRACT NUMBER \\
\hline & & 5b. GRANT NUMBER \\
\hline & & 5c. PROGRAM ELEMENT NUMBER \\
\hline \multirow{3}{*}{\multicolumn{2}{|c|}{$\begin{array}{l}\text { 6. AUTHOR(S) } \\
\text { Tang, Liang; DeCastro, Jonathan, A.; Zhang, Xiaodong ; Farfan-Ramos, Luis; Simon, } \\
\text { Donald, L. }\end{array}$}} & 5d. PROJECT NUMBER \\
\hline & & 5e. TASK NUMBER \\
\hline & & $\begin{array}{l}\text { 5f. WORK UNIT NUMBER } \\
\text { WBS 645846.02.07.03.12 }\end{array}$ \\
\hline \multicolumn{2}{|c|}{$\begin{array}{l}\text { 7. PERFORMING ORGANIZATION NAME(S) AND ADDRESS(ES) } \\
\text { National Aeronautics and Space Administration } \\
\text { John H. Glenn Research Center at Lewis Field } \\
\text { Cleveland, Ohio 44135-3191 }\end{array}$} & $\begin{array}{l}\text { 8. PERFORMING ORGANIZATION } \\
\text { REPORT NUMBER } \\
\text { E-17296 }\end{array}$ \\
\hline \multirow{2}{*}{\multicolumn{2}{|c|}{$\begin{array}{l}\text { 9. SPONSORING/MONITORING AGENCY NAME(S) AND ADDRESS(ES) } \\
\text { National Aeronautics and Space Administration } \\
\text { Washington, DC 20546-0001 }\end{array}$}} & $\begin{array}{l}\text { 10. SPONSORING/MONITOR'S } \\
\text { ACRONYM(S) } \\
\text { NASA }\end{array}$ \\
\hline & & $\begin{array}{l}\text { 11. SPONSORING/MONITORING } \\
\text { REPORT NUMBER } \\
\text { NASA/TM-2010-216360 }\end{array}$ \\
\hline \multicolumn{3}{|c|}{$\begin{array}{l}\text { 12. DISTRIBUTION/AVAILABILITY STATEMENT } \\
\text { Unclassified-Unlimited } \\
\text { Subject Category: } 07 \\
\text { Available electronically at http://gltrs.grc.nasa.gov } \\
\text { This publication is available from the NASA Center for AeroSpace Information, 443-757-5802 }\end{array}$} \\
\hline
\end{tabular}

\section{SUPPLEMENTARY NOTES}

\section{ABSTRACT}

A challenging problem in aircraft engine health management (EHM) system development is to detect and isolate faults in system components (i.e., compressor, turbine), actuators, and sensors. Existing nonlinear EHM methods often deal with component faults, actuator faults, and sensor faults separately, which may potentially lead to incorrect diagnostic decisions and unnecessary maintenance. Therefore, it would be ideal to address sensor faults, actuator faults, and component faults under one unified framework. This paper presents a systematic and unified nonlinear adaptive framework for detecting and isolating sensor faults, actuator faults, and component faults for aircraft engines. The fault detection and isolation (FDI) architecture consists of a parallel bank of nonlinear adaptive estimators. Adaptive thresholds are appropriately designed such that, in the presence of a particular fault, all components of the residual generated by the adaptive estimator corresponding to the actual fault type remain below their thresholds. If the faults are sufficiently different, then at least one component of the residual generated by each remaining adaptive estimator should exceed its threshold. Therefore, based on the specific response of the residuals, sensor faults, actuator faults, and component faults can be isolated. The effectiveness of the approach was evaluated using the NASA C-MAPSS turbofan engine model, and simulation results are presented.

15. SUBJECT TERMS

Systems health monitoring; Gas turbine engines; Fault detection

\begin{tabular}{|l|l|l|l|c|l|}
\hline \multicolumn{2}{|l|}{ 16. SECURITY CLASSIFICATION OF: } & $\begin{array}{l}\text { 17. LIMITATION OF } \\
\text { ABSTRACT }\end{array}$ & $\begin{array}{l}\text { 18. NUMBER } \\
\text { OF } \\
\text { PAGES }\end{array}$ & $\begin{array}{l}\text { 19a. NAME OF RESPONSIBLE PERSON } \\
\text { STI Help Desk (email:help@sti.nasa.gov) }\end{array}$ \\
\cline { 1 - 1 } $\begin{array}{l}\text { a. REPORT } \\
\text { U }\end{array}$ & $\begin{array}{l}\text { b. ABSTRACT } \\
\text { U }\end{array}$ & $\begin{array}{l}\text { c. THIS } \\
\text { PAGE } \\
\text { U }\end{array}$ & UU & 17 & $\begin{array}{l}\text { 19b. TELEPHONE NUMBER (include area code) } \\
\text { 4t43-757-5802 }\end{array}$ \\
\hline
\end{tabular}



